RESEARCH

\title{
BLADDER PRESERVATION WITH IMAGE- GUIDED RADIOTHERAPY FOR ELDERLY PATIENTS WITH MUSCLE-INVASIVE BLADDER CANCER: A SINGLE INSTUTION EXPERIENCE
}

Turkish Journal of Geriatrics

DOI: 10.31086/tigeri.2021.213

2021; 24(2): 174-184

- Özlem AYNACl ${ }^{1}$

- Lasif SERDAR ${ }^{1}$

- Ahmet Yaşar ZENGIN ${ }^{1}$

- Evrim SAVLI ${ }^{2}$

- Gonca Hanedan USLU1

- Sonay GEDIK ${ }^{1}$

CORRESPONDANCE

\section{${ }^{1}$ Özlem AYNACI}

Kanuni Training and Hospital, Radiation

Oncology Clinic, Trabzon, Turkey

\section{Phone: +905304047774}

e-mail: ozlemaynaci@gmail.com

Received: Mar 04, 2021

Accepted: May 16, 2021

${ }^{1}$ Kanuni Training and Hospital,, Radiation Oncology Clinic, Trabzon, Turkey

2 Samsun Training and Research Hospital, Radiation Oncology Clinic, Samsun, Turkey

\section{Abstract}

Introduction: The number of elderly patients with bladder cancer is expected to triple in the coming years in proportion to the increasing elderly population in the world. The aim of this study was to identify the prognostic factors affecting survival among elderly patients undergoing chemoradiotherapy for muscle-invasive bladder cancer.

Materials and Method: We retrospectively reviewed medical records from 93 biopsy-proven nonmetastatic elderly patients with bladder cancer $\geq 65$ years who were treated with helical tomotherapy. The patients received 64.8 Gy to the bladder with concurrent intravenous cisplatin $(40 \mathrm{mg} / \mathrm{m} 2)$ chemotherapy weekly as a radiosensitizer.

Results: The mean follow-up time was 34.1 months (range, 4.0-99.1 months). The two- and five-year overall survival, disease-free survival, and cancer-specific survival rates were $70.6 \%$, and $36.9 \%, 50.6 \%$ and $28.5 \%$, $89.1 \%$, and $58.5 \%$, respectively. Multivariate analysis indicated that urothelial obstruction was an independent prognostic factor affecting survival rates. No grade 4 adverse events and deaths attributable to treatment occurred during chemoradiotherapy

Conclusion: Image guided radiotherapy with chemotherapy as a bladdersparing approach is a tolerable alternative therapeutic option without severe acute and late toxicities in elderly patients who are unfit for radical cystectomy or refuse surgery.

Keywords: Radiotherapy, Image-Guided; Chemoradiotherapy; Urinary Bladder Neoplasms 


\section{INTRODUCTION}

Bladder cancer (BC) represents about $5 \%-10 \%$ of male cancers in Europe and United States and is the fourth most common cancer in men in the western world after prostate, lung, and colon cancers (1). Tobacco smoking and occupational exposure to aromatic amines are the most commonly accepted risk factors for BC. Age, stage, and gender are also the main recognized factors affecting the survival and prognosis of patients with $\mathrm{BC}(2)$.

BCs are often classified as non-muscle invasive, muscle-invasive, or metastatic. If left untreated, muscle-invasive bladder cancer (MIBC) is potentially lethal, with a five-year survival rate of $015 \%$. The mainstay treatment for MIBC is radical cystectomy and bilateral pelvic lymph node dissection with neoadjuvant cisplatin-based chemotherapy (3).

In recent years, there has been an increasing trend for organ-preserving approaches across multiple cancer types (e.g., breast, kidney, prostate, anal, and laryngeal cancers). This trend includes the development of various strategies involving definitive non-cystectomy surgical resection in combination with chemotherapy and radiation therapy (RT), which achieves five-year survival rates of $50 \%-60 \%$ and maintains an intact bladder in over $70 \%$ of patients (4). Although RT alone is a method of bladder preservation, the treatment response is lower at $56 \%$; there is also a relatively high rate of local recurrence or persistence that can lead to a need for salvage cystectomy (5).

The addition of chemotherapy to $\mathrm{RT}$ resulted in improved local control, good long-term bladder function, and a reduced rate of the need for cystectomy (6). Based on data from trials, RT alone has been avoided in cases who can tolerate concurrent chemoradiotherapy (CRT). However, concomitant therapy may be more challenging due to the severe hemotologic and renal toxicities. Bladder-preservation strategies are attractive for elderly patients with greater comorbidities who are not candidates for surgery (7), but it is also known that these patients cannot tolerate most chemotherapy regimens. In this study, we aimed to identify the prognostic factors affecting survival among elderly patients undergoing chemoradiotherapy for muscle-invasive bladder cancer.

\section{MATERIALS AND METHOD}

The current study protocol was approved by the Ethics Committee in our hospital. Data from 93 patients with biopsy-confirmed MIBC who underwent concurrent CRT between January 2011 and December 2018 at our Radiation Oncology Department were retrospectively reviewed. All the involved patients included either rejected surgery or were not suitable for surgery due to comorbidities. Table 1 shows the patient and tumor characteristics.

Cystoscopic evolution with transurethral resection (TUR) was applied prior to CRT. The American Joint Committee on Cancer 7th edition 2010 TNM staging system was used as a reference for tumor staging. Computed tomography (CT) and magnetic resonance imaging (MRI) were used to detect intrapelvic and regional lymph nodes.

\section{CRT}

RT was performed by a tomotherapy accelerator using $6 \mathrm{MV}$ photons and delivering a median total dose of $64.8 \mathrm{~Gy}$ (range, 40.6-66.6) in a 1.8 Gy/ fraction. Daily megavoltage computed tomography was acquired for patient positioning. Clinical target volume encompassed the urinary bladder, which was identified on contrast-enhanced CT or MRI with a $2 \mathrm{~cm}$ margin. In each fraction, an empty bladder was compulsory. Cisplatin at $40 \mathrm{mg} / \mathrm{m}^{2} /$ week was started on day 1 and given within 60 minutes of IV infusion, which was continued weekly until the last week.

Total blood counts and kidney function tests were performed weekly, and chemotherapy dose reduction was applied when $\geq$ grade 3 hemotologic and renal toxicities were experienced 
Table 1. Patient and tumor characteristics

\begin{tabular}{|c|c|}
\hline Characteristic & n (\%) \\
\hline \multicolumn{2}{|l|}{ Gender } \\
\hline Male & $84(90.3)$ \\
\hline Female & $9(9.7)$ \\
\hline \multicolumn{2}{|l|}{ Age (years) } \\
\hline Mean \pm SD & $73.86 \pm 9.1$ \\
\hline Range & $44-91$ \\
\hline \multicolumn{2}{|l|}{ Tumor size $(\mathrm{cm})$} \\
\hline$\leq 5$ & $46(49.5)$ \\
\hline$>5$ & $18(19.4)$ \\
\hline Unknown & $29(31.1)$ \\
\hline \multicolumn{2}{|l|}{ Procedure } \\
\hline Complete TUR & $29(31.9)$ \\
\hline Incomplete TUR & $62(68.1)$ \\
\hline \multicolumn{2}{|l|}{ Histopathological type } \\
\hline LGPUC & $6(6.5)$ \\
\hline HGPUC & $72(77.4)$ \\
\hline Mixt, Other & $15(16.1)$ \\
\hline \multicolumn{2}{|l|}{ T Stage } \\
\hline I & $4(4.3)$ \\
\hline ॥ & $70(75.3)$ \\
\hline IIla & $9(9.7)$ \\
\hline IIlb & - \\
\hline IVa & $10(10.7)$ \\
\hline \multicolumn{2}{|l|}{ Node Status } \\
\hline NO & $80(89.9)$ \\
\hline $\mathrm{N} 1-2$ & $9(10.1)$ \\
\hline \multicolumn{2}{|l|}{ Grade } \\
\hline |- || & $6(6.5)$ \\
\hline III-IV & $87(93.5)$ \\
\hline \multicolumn{2}{|l|}{ Urothelial obstruction } \\
\hline No & $76(82.6)$ \\
\hline Yes & $16(17.4)$ \\
\hline
\end{tabular}

Abbreviations:TUR=transurethral resection of the bladder, HGPUC = high-grade papillary urothelial carcinoma, LGPUC= low-grade papillary urothelial carcinoma; Mixt = adenosquamos; Other = Squamos, adeno cancer, undifferentiated carcinoma, small cell carcinoma.

\section{Evaluation and follow-up}

Tumor response was assessed through a combination of cystoscopy and CT four to six weeks after finishing treatment. Subsequent radiologic and cystoscopic follow-up was performed once every three months for two years and then once every six months.

\section{Statistical analysis}

The analysis was performed using SPSS version 13 software. Overall survival (OS) was calculated from the completion of CRT to the date of death or last follow-up. Disease-free survival (DFS) was defined as the time from the completion of CRT to the date of local recurrence or progression. Cancer-specific survival (CSS) was documented as the time from completion of CRT to death due to disease.

Kaplan-Meier survival analysis was used to examine the distribution of survival times. A Log-rank test was used to determine the difference in survival between the groups. Bonferroni correction was applied in the comparisons between the groups. In the multivariate analysis, independent predictors of survival were examined using Cox regression analysis. Chi-square and Fisher's exact test were used to determine the factors influencing treatment response. Cases below $5 \%$ of type- 1 error levels were accepted as statistically significant.

\section{RESULTS}

\section{Patients and tumor characteristics}

A total of 93 patients were included in this study. The mean follow-up time was 34.1 months (range, 4.0-99.1 months). By the end of the follow-up period, 39 patients were still alive while 54 had died. The median age of patients was 75 years (range, 44-91). Data showed a clear male preponderance of approximately 9.3:1. Overall, $77.4 \%$ of the patients had high-grade disease. About $32 \%$ of the patients 
had undergone complete TUR, and 68\% underwent incomplete TUR. Table 1 summarizes the patient characteristics.

\section{Proportional hazards analysis}

Multivariate and univariate analyses were used to provide quantitative estimates of the association of the following 10 clinical and pathological tumor factors with OS, DFS, and CSS in the 93 patients studied: age ( $<70$ and $>70)$, gender, tumor histology, tumor size $(5 \mathrm{~cm}$ and $>5 \mathrm{~cm}$ ), tumor grade (good, medium, and poor or undifferentiated), T stage (1, 2 , and 3-4), nodal status, urothelial obstruction, initial TUR procedure (complete or incomplete), and treatment response.

The results of univariate analysis to determine the prognostic factors showed that urothelial obstruction $(P=0.013)$ and treatment response $(p<0.001)$ had significant effects on OS. TUR procedure $(\mathrm{P}=$ 0.062 ) was closely significant (Table 2 ). The multivariate analysis revealed a significant relationship between urothelial obstruction and OS (hazard ratio [HR]: 1.5; 95\% Cl: 3.6 (1.4-9.3); $P=0.007$ ) (Table 3).

Urothelial obstruction ( $P=0.038)$, TUR procedure $(P=0.047)$ and treatment response $(p<0.001)$ had significant effects on DFS in the univariate analysis (Table 4). The multivariate analysis indicated that urothelial obstruction (HR: 1.5; 95\% Cl: 5.6 (1.8-17.3); $P=0.003$ ) was significant (Table 3).

From univariate analyses, the variables determined as statistically significant prognostic factors on CSS included urothelial obstruction $(p<0.001)$ and treatment response $(P=0.001)$ (Table 5). Multivariate analysis indicated that urothelial obstruction (HR: 1.5; 95\% Cl: 2.7 (1.1-6.5); $P=0.031)$ was significant (Table 3).

\section{Overall Survival}

The median OS was 36.6 months (\%95 GI: 19.653.7). The two- and five-year OS rates were $70.6 \%$ and $36.9 \%$, respectively (Figure 1). The overall actuarial survival was significantly better among the 60 patients with complete responses than among the 25 with incomplete responses to the CRT. The fiveyear OS rate was $49.1 \%$ for patients with complete responses but dropped to $10.6 \%$ for patients with incomplete responses $(p<0.001)$. The 76 patients who did not have urothelial obstruction at presentation had significantly better OS. The two-year OS rate was $74.4 \%$ for patients without urothelial obstruction at presentation but dropped to $57.4 \%$ for patients with urothelial obstruction $(P=0.007)$.

\section{Disease-Free Survival}

The median DFS was 24.5 months (\%95 Cl: 14.534.6). The two- and five-year DFS rates were $50.6 \%$ and $28.5 \%$, respectively. The 29 patients with initial complete TUR had significantly better DFS than did the 62 with incomplete TUR. The five-year DFS rate was $50.7 \%$ for patients who underwent complete TUR but dropped to $20.9 \%$ for patients with complete TUR $(P=0.047)$. The overall actuarial survival was significantly better among the 60 patients with complete responses than among the 25 with incomplete responses to the CRT. The five-year DFS rate was $39 \%$ for patients with complete responses but dropped to $6.4 \%$ for patients with incomplete responses $(p<0.001)$. OS was significantly better among the 76 patients who did not have urothelial obstruction at presentation. The two-year DFS rate was $54.3 \%$ for patients without urothelial obstruction at presentation but dropped to $36.5 \%$ for patients with urothelial obstruction $(P=0.038)$.

\section{Cancer-Specific Survival}

The median CSS was 69.3 months (\%95 Cl: 39.699). The two- and five-year CSS rates were $89.1 \%$ and $59.5 \%$, respectively. The overall actuarial survival among the 60 patients with complete responses was significantly better than among the 25 with incomplete responses to the CRT. The five-year CSS 
Table 2. Results of log-rank univariate analysis for overall survival

\begin{tabular}{|c|c|c|c|c|c|}
\hline Variable & $n$ & $\begin{array}{l}\text { Median Survival } \\
\qquad(95 \% \mathrm{Cl})\end{array}$ & $\begin{array}{l}\text { 2-y OS } \\
\text { (\%) ( }( \pm S E)\end{array}$ & $\begin{array}{l}\text { 5-y OS } \\
(\%)( \pm S E)\end{array}$ & $p$ value \\
\hline $\begin{array}{c}\text { Age (year) } \\
<70 \\
70 \leq\end{array}$ & $\begin{array}{l}23 \\
70\end{array}$ & $\begin{array}{l}57.4(38.8-76.0) \\
46.3(38.1-54.5)\end{array}$ & $\begin{array}{l}74.8( \pm 0.11) \\
69.7( \pm 0.06)\end{array}$ & $\begin{array}{l}58.2( \pm 0.14) \\
32.4( \pm 0.07)\end{array}$ & 0.345 \\
\hline $\begin{array}{l}\text { Gender } \\
\qquad \begin{array}{l}\text { Male } \\
\text { Female }\end{array}\end{array}$ & $\begin{array}{c}84 \\
9\end{array}$ & $\begin{array}{l}36.6(21.6-51.7) \\
24.5(19.0-30.1)\end{array}$ & $\begin{array}{l}71.5( \pm 0.05) \\
62.5( \pm 0.17)\end{array}$ & $\begin{array}{c}38.5( \pm 0.07) \\
25( \pm 0.15)\end{array}$ & 0.363 \\
\hline $\begin{array}{l}\text { Tumor diameter }(\mathrm{cm}) \\
\quad \leq 5 \\
\quad>5\end{array}$ & $\begin{array}{l}46 \\
18\end{array}$ & $\begin{array}{l}55.2(15.2-95.3) \\
33.5(13.8-53.3)\end{array}$ & $\begin{array}{l}74( \pm 0.07) \\
75( \pm 0.11)\end{array}$ & $\begin{array}{l}46.6( \pm 0.09) \\
32.1( \pm 0.13)\end{array}$ & 0.455 \\
\hline $\begin{array}{l}\text { Tumor histologic } \\
\text { LGPUC } \\
\text { HGPUC } \\
\text { Mixt, Other }\end{array}$ & $\begin{array}{c}6 \\
72 \\
15\end{array}$ & $\begin{array}{c}54.4(2.5-106.3) \\
33.5(26.9-40.2) \\
67.9(0-136.9)\end{array}$ & $\begin{array}{l}66.7( \pm 0.19) \\
69.5( \pm 0.06) \\
76.9( \pm 0.12)\end{array}$ & $\begin{array}{c}50( \pm 0.20) \\
30.7( \pm 0.07) \\
52.7( \pm 0.14)\end{array}$ & 0.305 \\
\hline $\begin{array}{l}\text { Histologic grade } \\
\qquad \begin{array}{c}\text { G1-G2 } \\
\text { G3-G4 }\end{array}\end{array}$ & $\begin{array}{c}6 \\
87\end{array}$ & $\begin{array}{l}54.4(2.5-106.3) \\
34.4(23.2-45.6)\end{array}$ & $\begin{array}{l}66.7( \pm 0.19) \\
70.9( \pm 0.05)\end{array}$ & $\begin{array}{c}50( \pm 0.20) \\
35.8( \pm 0.06)\end{array}$ & 0.835 \\
\hline $\begin{array}{c}\text { T Stage } \\
\text { T1 } \\
\text { T2 } \\
\text { T3-4 }\end{array}$ & $\begin{array}{c}4 \\
70 \\
19\end{array}$ & $\begin{array}{c}17.9(6.8-29.1) \\
36.6(18.2-55.1) \\
33.5(0-72.9)\end{array}$ & $\begin{array}{l}33.3( \pm 0.27) \\
70.6( \pm 0.06) \\
76.5( \pm 0.10)\end{array}$ & $\begin{array}{l}33.3( \pm 0.27) \\
39.5( \pm 0.07) \\
27.9( \pm 0.13)\end{array}$ & 0.878 \\
\hline $\begin{array}{c}\text { Node Status } \\
\text { N0 } \\
\text { N1-2 }\end{array}$ & $\begin{array}{c}80 \\
9\end{array}$ & $\begin{array}{c}40.4(23.2-57.5) \\
29.6(0.2-59.1)\end{array}$ & $\begin{array}{l}73.8( \pm 0.05) \\
66.7( \pm 0.16)\end{array}$ & $\begin{array}{l}38.4( \pm 0.07) \\
22.2( \pm 0.19)\end{array}$ & 0.511 \\
\hline $\begin{array}{l}\text { Urothelial obstruction } \\
\qquad \text { No } \\
\text { Yes }\end{array}$ & $\begin{array}{l}76 \\
16\end{array}$ & $\begin{array}{l}49.9(29.9-69.9) \\
29.6(16.6-42.7)\end{array}$ & $\begin{array}{l}74.4( \pm 0.05) \\
57.4( \pm 0.13)\end{array}$ & $\begin{array}{c}42.9( \pm 0.07) \\
0\end{array}$ & 0.013 \\
\hline $\begin{array}{l}\text { Procedure } \\
\text { Complete TUR } \\
\text { Incomplete TUR }\end{array}$ & $\begin{array}{l}29 \\
62\end{array}$ & $\begin{array}{l}65.1(31.3-98.8) \\
29.6(22.4-36.9)\end{array}$ & $\begin{array}{l}79.1( \pm 0.08) \\
67.9( \pm 0.06)\end{array}$ & $\begin{array}{l}54.1( \pm 0.12) \\
30.5( \pm 0.07)\end{array}$ & 0.075 \\
\hline $\begin{array}{l}\text { Treatment response } \\
\qquad \begin{array}{l}\text { No } \\
\text { Yes }\end{array}\end{array}$ & $\begin{array}{l}25 \\
60\end{array}$ & $\begin{array}{l}24.5(12.6-36.5) \\
55.2(36.5-73.9)\end{array}$ & $\begin{array}{l}50.1( \pm 0.10) \\
81.3( \pm 0.05)\end{array}$ & $\begin{array}{l}10.6( \pm 0.09) \\
49.1( \pm 0.08)\end{array}$ & $<0.001$ \\
\hline
\end{tabular}

Abbreviations: TUR=transurethral resection of the bladder, HGPUC=high-grade papillary urothelial carcinoma, LGPUC=low-grade papillary urothelial carcinoma. 
Table 3. Results of multivariate analysis for overall survival, cause-specific survival and disease-free survival by Cox proportional hazard model

\begin{tabular}{|c|c|c|c|c|c|c|}
\hline \multirow[b]{2}{*}{ Variable } & \multicolumn{2}{|c|}{ Overall survival } & \multicolumn{2}{|c|}{ Cause-specific survival } & \multicolumn{2}{|c|}{ Disease-free survival } \\
\hline & $\begin{array}{c}\text { Hazard } \\
\text { Ratio }(95 \% \mathrm{Cl})\end{array}$ & $\begin{array}{r}p \\
\text { value }\end{array}$ & $\begin{array}{c}\text { Hazard Ratio } \\
\qquad(95 \% \mathrm{Cl})\end{array}$ & $\begin{array}{r}p \\
\text { value }\end{array}$ & $\begin{array}{l}\text { Hazard Ratio } \\
(95 \% \mathrm{Cl})\end{array}$ & $p$ value \\
\hline \multicolumn{7}{|l|}{ Age (year) } \\
\hline$<70$ vs $70 \leq$ & $1.9(0.6-5.3)$ & 0.255 & $1.1(0.3-4.2)$ & 0.851 & $1.3(0.5-3.3)$ & 0.542 \\
\hline \multicolumn{7}{|l|}{ Gender } \\
\hline Male vs Female & $0.8(0.2-2.6)$ & 0.665 & $2.2(0.6-8.6)$ & 0.247 & $0.8(0.2-2.7)$ & 0.677 \\
\hline \multicolumn{7}{|l|}{ Tumor diameter $(\mathrm{cm})$} \\
\hline $5 \leq$ vs $>5$ & $1.0(0.4-2.4)$ & 0.990 & $0.9(0.3-2.8)$ & 0.894 & $0.9(0.4-2.1)$ & 0.778 \\
\hline \multicolumn{7}{|l|}{ Tumor histologic } \\
\hline LGPUC vs HGPUC & $0.5(0.1-2.4)$ & $\begin{array}{l}0.449 \\
0.410\end{array}$ & $2.2(0.2-22.6)$ & $\begin{array}{l}0.392 \\
0.503\end{array}$ & $0.6(0.1-2.6)$ & $\begin{array}{l}0.405 \\
0.501\end{array}$ \\
\hline LGPUC vs Mixt, Other & $0.3(0.1-1.9)$ & 0.214 & $0.8(0.1-10.1)$ & 0.831 & $0.3(0.1-1.9)$ & 0.218 \\
\hline \multicolumn{7}{|l|}{ T Stage } \\
\hline T2 vs T1 & $1.6(0.2-13.5)$ & 0.641 & $0.9(0.4-1.2)$ & $\begin{array}{l}0.304 \\
0.986\end{array}$ & $0.8(0.1-6.5)$ & $\begin{array}{l}0.643 \\
0.849\end{array}$ \\
\hline T2 vs T3-4 & $1.5(0.6-3.9)$ & 0.383 & $2.5(0.8-8.1)$ & 0.123 & $1.5(0.6-3.5)$ & 0.372 \\
\hline \multicolumn{7}{|l|}{ Node Status } \\
\hline No vs N1-2 & $0.6(0.1-2.8)$ & 0.507 & $0.9(0.2-4.6)$ & 0.899 & $0.7(0.2-3.3)$ & 0.676 \\
\hline \multicolumn{7}{|l|}{ Urothelial obstruction } \\
\hline No vs Yes & $3.6(1.4-9.3)$ & 0.007 & $5.6(1.8-17.3)$ & 0.003 & $2.7(1.1-6.5)$ & 0.031 \\
\hline
\end{tabular}

Abbreviations: $\mathrm{Cl}=$ confidence interval; $\mathrm{HGPUC}=$ high-grade papillary urothelial carcinoma; LGPUC=low-grade papillary urothelial carcinoma.

rate was $69.6 \%$ for patients with complete responses but dropped to $35.4 \%$ for patients with incomplete responses $(P=0.001)$. CSS was significantly better among the 76 patients who did not have urothelial obstruction at presentation. The two-year CSS rate was $93.3 \%$ for patients without urothelial obstruction at presentation but dropped to $68.4 \%$ for patients with urothelial obstruction ( $\leq \leq 0.001)$.

\section{Toxicity}

Grade 1 and 2 toxicities could not be evaluated due to the missing files and records of the patients. We recorded higher grade toxicities from registered nurses orders and patient recipes. Concurrent chemotherapy was interrupted in an overall four pa- tients due to grade 3 hematological toxicities were observed. The percentages of patients sustaining acute bladder irradiation, fatigue, and diarrhea were $32 \%, 43 \%$, and $10 \%$, respectively. There were no late grade 4 toxicities and deaths attributable to the treatment.

\section{DISCUSSION}

Population aging is a shift in the distribution of people toward older ages with increasing life expectancy. Although age is known as a poor prognostic factor, the geriatric patient population is a heterogeneous group, and the chronological age of the patient does not always reflect their actual health status (8). To choose treatments wisely, an estimate 
Table 4. Results of log-rank univariate analysis for disease-free survival

\begin{tabular}{|c|c|c|c|c|c|}
\hline Variable & $\mathrm{n}$ & $\begin{array}{c}\text { Median Survival } \\
(95 \% \mathrm{Cl})\end{array}$ & 2-y DFS (\%) & 5-y DFS (\%) & $p$ value \\
\hline $\begin{array}{c}\text { Age (year) } \\
<70 \\
70 \leq\end{array}$ & $\begin{array}{l}23 \\
70\end{array}$ & $\begin{array}{c}14.9(4.4-25.3) \\
28(18-38)\end{array}$ & $\begin{array}{l}40.9 \\
53.2\end{array}$ & $\begin{array}{l}40.9 \\
25.2\end{array}$ & 0.825 \\
\hline $\begin{array}{l}\text { Gender } \\
\text { Male } \\
\text { Female }\end{array}$ & $\begin{array}{c}84 \\
9\end{array}$ & $\begin{array}{c}25.5(14.9-36.2) \\
17.9(7.5-28.3)\end{array}$ & $\begin{array}{c}50.7 \\
50\end{array}$ & $\begin{array}{c}28.7 \\
25\end{array}$ & 0.679 \\
\hline $\begin{array}{l}\text { Tumor diameter }(\mathrm{cm}) \\
\leq 5 \\
>5\end{array}$ & $\begin{array}{l}46 \\
18\end{array}$ & $\begin{array}{c}32.3(8.9-55.8) \\
40.4(0-86.7)\end{array}$ & $\begin{array}{l}53.4 \\
57.1\end{array}$ & $\begin{array}{l}35.2 \\
34.8\end{array}$ & 0.686 \\
\hline $\begin{array}{l}\text { Tumor histologic } \\
\text { LGPUC } \\
\text { HGPUC } \\
\text { Mixt, Other }\end{array}$ & $\begin{array}{c}6 \\
72 \\
15\end{array}$ & $\begin{array}{c}14.9(0-54) \\
21.9(13.5-30.2) \\
67.2(0-134.9)\end{array}$ & $\begin{array}{c}50 \\
46.7 \\
69.2\end{array}$ & $\begin{array}{l}33.3 \\
20.9 \\
52.7\end{array}$ & 0.170 \\
\hline $\begin{array}{l}\text { Histologic grade } \\
\text { G1-G2 } \\
\text { G3-G4 }\end{array}$ & $\begin{array}{c}6 \\
87\end{array}$ & $\begin{array}{c}14.9(0-54) \\
24.5(14.9-34.2)\end{array}$ & $\begin{array}{c}50 \\
50.7\end{array}$ & $\begin{array}{l}33.3 \\
28\end{array}$ & 0.505 \\
\hline $\begin{array}{l}\text { T Stage } \\
\text { T1 } \\
\text { T2 } \\
\text { T3-4 }\end{array}$ & $\begin{array}{c}4 \\
70 \\
19\end{array}$ & $\begin{array}{c}17.9(6.8-29.1) \\
25.5(14-37.1) \\
24.5(0-52)\end{array}$ & $\begin{array}{l}33.3 \\
50.5 \\
53.5\end{array}$ & $\begin{array}{l}33.3 \\
27.8 \\
28.5\end{array}$ & 0.979 \\
\hline $\begin{array}{l}\text { Node Status } \\
\text { N0 } \\
\text { N1-2 }\end{array}$ & $\begin{array}{c}80 \\
9\end{array}$ & $\begin{array}{l}25.5(14.5-36.6) \\
29.6(19.8-39.4)\end{array}$ & $\begin{array}{l}51.5 \\
55.6\end{array}$ & $\begin{array}{l}28.2 \\
27.8\end{array}$ & 0.906 \\
\hline $\begin{array}{l}\text { Urothelial obstruction } \\
\text { No } \\
\text { Yes }\end{array}$ & $\begin{array}{l}76 \\
16\end{array}$ & $\begin{array}{c}31.8(13.4-50.2) \\
19.1(7.1-31.2)\end{array}$ & $\begin{array}{l}54.3 \\
36.5\end{array}$ & $\begin{array}{c}33.1 \\
0\end{array}$ & 0.038 \\
\hline $\begin{array}{l}\text { Procedure } \\
\text { Complete TUR } \\
\text { Incomplete TUR }\end{array}$ & $\begin{array}{l}29 \\
62\end{array}$ & $\begin{array}{c}65(25.1-105) \\
21.1(14.8-27.5)\end{array}$ & $\begin{array}{l}71.9 \\
43.3\end{array}$ & $\begin{array}{l}50.7 \\
20.9\end{array}$ & 0.047 \\
\hline $\begin{array}{l}\text { Treatment response } \\
\text { No } \\
\text { Yes }\end{array}$ & $\begin{array}{l}25 \\
60\end{array}$ & $\begin{array}{c}43.5(21.5-65.6) \\
10.7(6.5-15)\end{array}$ & $\begin{array}{l}21.2 \\
63.2\end{array}$ & $\begin{array}{l}6.4 \\
39\end{array}$ & $<0.001$ \\
\hline
\end{tabular}

Abbreviations: TUR=transurethral resection of the bladder, HGPUC = high-grade papillary urothelial carcInoma, LGPUC=IOW-grade papillary urothelial carcinoma; Mixt = adenosquamos;

Other = Squamos, adeno cancer, undifferentiated carcinoma, small cell carcinoma.

of life expectancy should be considered against the risk of cancer relapse or cancer-related death during treatment plan.

$B C$ is an age-associated malignancy with increased prevalence in patients aged $\geq 65$ years (9). Bladder tumors are the fourth most frequently diagnosed cancer type in males and the ninth in females (10). The histological grade of BC is eventu- ally determined by examining the resected tumor. The most widely used classification for grading nonMIBC (G1, G2, and G3) was the 1973 World Health Organization (WHO) classification (11). However, a revised grading system for urothelial carcinoma (low grade and high grade) was proposed and adopted by the WHO in 2004 to replace the 1973 classification system. The natural history of $B C$ is heteroge- 
neous, ranging from a low-grade variant to a highgrade subtype $(12,13)$. Wakai et al. reported the distribution of tumor grades were as follows: $74 \%$ high grade and $26 \%$ low grade (14). In our study high, low, and mixed grades were present in $77 \%$, $7 \%$, and $16 \%$ of patients, respectively.

Thus far, bladder-sparing approaches using RT alone have not yielded comparable results with radical cystectomy and lymphadenectomy. To improve the efficacy of radical RT, neoadjuvant or concomitant chemotherapy has been administered. Currently, platinum-based chemotherapy has been advocated for CRT as an alternative to radical cystectomy in MIBC (15). The most comprehensive TUR for invasive BC, followed by RT with the concurrent administration of cisplatin, was fairly well tolerated by the patients we studied. Treatment-related toxicities are generally reversible and comparable and are slightly lower than with other studies (16). The typical dose schedules of RT would be 64 Gy in 32 fractions or hypofractionated schedules such as $55 \mathrm{~Gy}$ in 20 fractions. Many studies have used 64-66 Gy, but the definite optimal RT dose is unknown (17). Korpics et al. conducted a retrospective cohort study involving 843 patients with cT2-4 NO-3 M0 transitional cell MIBC treated with RT and found that patients receiving RT were more likely to receive an RT dose of $60 \mathrm{~Gy}$. The two-year OS rates, when divided by RT doses, were $26 \%, 31 \%$, $56 \%$, and $55 \%$ for $<50,50-59,60-66$, and $>66$ Gy, respectively, and analyses showed that $<50$ Gy doses were associated with worse survival outcomes (18). In our study, we utilized $64 \mathrm{~Gy}$, and the two-year OS rate was $70.6 \%$. The obtained OS rate was higher than that in Korpics et al.'s study, and this difference could be due to the addition of chemotherapy and RT technique.

Neoadjuvant or concomitant chemotherapy has been added to improve the efficacy of radical RT. The addition of chemotherapy is aimed to eliminate the micrometastases and increase the radiation sensitivity. In this way, the Radiation Oncology
Group (RTOG) designed a series of studies that examined the efficacy of peritreatment chemotherapy. In the first study, RTOG 8512, 64 Gy RT with cisplatin was administered in 42 patients. The five-year OS rate with radiosensitizing cisplatin was $52 \%$ (19). The RTOG 99-06 study assessed the effect of chemotherapeutic agents on the weekly use of cisplatin and paclitaxel simultaneously with RT, and the five-year OS rate was reported to be $50 \%$ (20). The five-year survival reported by other authors ranged from $47 \%$ to $54 \%$. Concurrent chemotherapy was continued in $80.7 \%$ of patients. Gemcitabine was interrupted due to grade 3 thrombocytopenia in one patient (21). In our study, we found a five-year OS rate of $36.9 \%$, which is lower than those of other studies. This result may be due to the inclusion of more patients undergoing incomplete TUR and our cohort being older. Concurrent chemotherapy was given as a part of CRT in 89 patients (95.6\%).

There are two randomized trials of radiosensitization using UK schedules: the BC2001 and BCON studies. These trials use radiosensitization with either concurrent chemotherapy (BC2001) or carbogen and nicotinamide (BCON). BC2001 has shown significant improvement in DFS with concurrent 5 -fluorouracil and mitomycin C of $34 \%(22,23)$. Hussain et al. reported a phase I/II study of synchronous CRT with mitomycin C and 5-FU in 41 patients and obtained two- and five-year OS rates of $49 \%$ and $36 \%$, respectively (24). In our study, we found the two-year OS rates were $70.6 \%$ respectively, which is higher than those of the above-mentioned trials due to the addition of cisplatin.

The radicality of TUR in bladder-sparing treatment was reported to be an independent prognostic factor for the survival of patients with MIBC. Asadauskienè et al. showed a statistically significant difference between complete and incomplete TUR in terms of OS. Data from this study demonstrated an impact of patient age, $T$ stage, and dose of radiation on survival of patients treated by radiotherapy. (25). In the current study, we characterized urothelial 
Table 5. Results of log-rank univariate analysis for cause-specific survival

\begin{tabular}{|c|c|c|c|c|c|}
\hline Variable & $\mathrm{n}$ & $\begin{array}{l}\text { Median Survival } \\
\qquad(95 \% \mathrm{Cl})\end{array}$ & $\begin{array}{c}2-y \text { CSS } \\
(\%)\end{array}$ & $\begin{array}{c}\text { 5-y CSS } \\
(\%)\end{array}$ & $P$ value \\
\hline \multicolumn{6}{|l|}{ Age (year) } \\
\hline$<70$ & 23 & $63.9(46.9-80.8)$ & 84.6 & 65.8 & 0.731 \\
\hline $70 \leq$ & 70 & $65.9(55.7-76)$ & 89.9 & 57.4 & \\
\hline \multicolumn{6}{|l|}{ Gender } \\
\hline Male & 84 & 81.5 (65-98.1) & 89.6 & 63.6 & 0.256 \\
\hline Female & 9 & $25.4(0-61.2)$ & 83.3 & 33.3 & \\
\hline \multicolumn{6}{|l|}{ Tumor diameter (cm) } \\
\hline$\leq 5$ & 46 & $69.3(53.3-85.3)$ & 88.6 & 66.2 & 0.357 \\
\hline$>5$ & 18 & $40.4(13.1-67.6)$ & 85.7 & 36.7 & \\
\hline \multicolumn{6}{|l|}{ Tumor histologic } \\
\hline LGPUC & 6 & $77.3(64.3-90.2)$ & 100 & 75 & 0215 \\
\hline HGPUC & 72 & $61.1(50.4-71.7)$ & 86 & 52.8 & 0.243 \\
\hline Mixt, Other & 15 & $79.3(60.8-97.8)$ & 100 & 80 & \\
\hline \multicolumn{6}{|l|}{ Histologic grade } \\
\hline G1-G2 & 6 & $77.3(64.3-90.2)$ & 100 & 75 & 0.360 \\
\hline G3-G4 & 87 & $65.8(56.2-75.4)$ & 88.4 & 59.4 & \\
\hline \multicolumn{6}{|l|}{ T Stage } \\
\hline $\mathrm{T} 1$ & 4 & 80.1 (63.2-97) & 100 & 100 & (201 \\
\hline $\mathrm{T} 2$ & 70 & $70.8(60.7-81)$ & 89.1 & 68.7 & 0.204 \\
\hline T3-4 & 19 & $51.6(34.5-68.7)$ & 87.1 & 31.7 & \\
\hline \multicolumn{6}{|l|}{ Node Status } \\
\hline NO & 80 & 81.5 (59.5-103.5) & 90.4 & 60 & 0.339 \\
\hline N1-2 & 9 & $34.3(4.6-64)$ & 76.2 & 38.1 & \\
\hline \multicolumn{6}{|l|}{ Urothelial obstruction } \\
\hline No & 76 & $97(65-128.9)$ & 93.3 & 67.9 & $<0.001$ \\
\hline Yes & 16 & $33.5(13.8-53.3)$ & 68.4 & 0 & \\
\hline \multicolumn{6}{|l|}{ Procedure } \\
\hline Complete TUR & 29 & 73.9 (57.4-90.3) & 91.1 & 62.3) & 0.371 \\
\hline Incomplete TUR & 62 & $63.7(52.4-75)$ & 87.7 & 58 & \\
\hline \multicolumn{6}{|l|}{ Treatment response } \\
\hline No & 25 & $48.1(27.8-68.4)$ & 75.1 & 35.4 & 0.001 \\
\hline Yes & 60 & 74.9 (64.9-84.9) & 94 & 69.6 & \\
\hline
\end{tabular}

Abbreviations: TUR=transurethral resection of the bladder, $\mathrm{HGPUC}=$ high-grade papillary urothelial carcinoma, LGPUC= low-grade papillary urothelial carcinoma 
obstruction and the status of treatment response as significant prognostic factors that predict OS and CSS in the univariate analysis. However, the status of treatment response lost its statistical significance when included in a multivariate analysis with the factors that were significantly associated with survival in the univariate analysis. Considering the likelihood of 76 patients without urothelial obstruction surviving two years with a functioning, treated bladder $(54.3 \%)$, the bladder-sparing approach is relatively encouraging compared to $16(36.5 \%)$ patients with urothelial obstruction.

\section{Study Limitations}

Our study includes the following limitations: first, our study was single institutional and retrospective; and second, T stage was not detected as a signifi-

\section{REFERENCES}

1. Siegel RL, Miller KD, Jemal A. Cancer statistics. Cancer J. Clin. 2017; 67(1): 7-30. (PMID: 28055103)

2. Lobo N, Mount C, Omar K, et al. Landmarks in the treatment of muscle-invasive bladder cancer. Nat Rev Urol 2017; 14(9): 565-574. (PMID: 28675174)

3. Leow JJ, Reese S, Trinh QD, Bellmunt et al. Impact of surgeon volume on the morbidity and costs of radical cystectomy in the USA: a contemporary population-based analysis. BJU International 2015;115(5): 713-721. (PMID: 24674655)

4. Giacalone NJ, Shipley WU, Clayman RH, et al. Longterm outcomes after bladder-preserving tri-modality therapy for patients with muscle-invasive bladder cancer: an updated analysis of the Massachusetts General Hospital Experience. Eur Urol 2017; 71(6): 952-960. (PMID: 28081860)

5. Jahnson S, Pedersen J, Westman G. Bladder carcinoma - a 20-year review of radical irradiation therapy. Radiother Oncol 1991; 22(2): 111-117. (PMID: 1957001)

6. Hamad J, McCloskey H, Milowsky M, et al. Bladder preservation in muscle-invasive bladder cancer: a comprehensive review. International Braz J Urol 2020: 46(2); 184-169. (PMID: 31961624) cant prognostic factor for a relatively small number of patients.

\section{CONCLUSION}

Our study supports the utilization of CRT for BC in routine practice. Concomitant cisplatin was administered in all patients without any omission due to toxicity. There was no grade 3 intestinal or genitourinary side effects recorded. Grade 3 hematologic post-treatment toxicity occurred in four patients.

The authors declare no conflict of interest.

Funding: The funders had no role in the study design, data collection, and analysis, decision to publish, or preparation of the manuscript.

7. Turgeon AN, Souhami L. Trimodality therapy for bladder preservation in elderly population with invasive bladder cancer. Front Oncol 2014: 4(206): 1-9. (PMID: 25140295)

8. Tekin A, Şengör F. The place of radical cystectomy in treatment of bladder cancer in elderly Turkish Journal of Urology 2006; 32(1): 8-13. (in Turkish)

9. Jemal A, Siegel R, XU J. Ward E: Cancer statistics. CA Cancer J Clin 2010; 60(5): 277-300. (PMID: 20610543)

10. Shariat SF, Sfakianos JP, Droller MJ, et al. The effect of age and gender on bladder cancer: a critical review of the literature. BJU Int 2009; 105(3): 300-308. (PMID: 19912200)

11. Nuclear morphometry in typing and grading urothelial neoplasms of urinary bladder. Turkish Pathology Journal 2007: 23(11); 16-20. (in Turkish)

12. Kirkali Z, Chan T, Manoharan M, et al. Bladder cancer: epidemiology, staging and grading, and diagnosis. Urology 2005; 66(Suppl 1): 4-34. (PMID: 16399414)

13. lida $\mathrm{S}$, Kondo $\mathrm{T}$, Kobayashi $\mathrm{H}$, et al. Clinical outcome of high-grade non-muscle-invasive bladder cancer: a long-term single center experience. Int J Urol 2009; 16(3): 287-292. (PMID: 19207115)

14. Wakai K, Utsumi T, Oka R, et al. Clinical predictors for high-grade bladder cancer before first-time tran- 
surethral resection of the bladder tumor: a retrospective cohort study. Japanese $\mathrm{J}$ of Clinical Oncology 2016; 46(10): 964-967. (PMID: 27511986)

15. Kaufman DS, Shipley WU, Griffin PP, et al. Selective bladder preservation by combination treatment of invasive bladder cancer. N Engl J Med. 1993; 329(19): 1377-1382. (PMID: 8413433)

16. Shipley WU, Kaufman DS, Zehr E, et al. Selective bladder preservation by combined modality protocol treatment: long term outcomes of 190 patients with invasive bladder cancer. Urology 2002; 60(1): 6268. (PMID: 12100923)

17. Zhang S, Yu YH, Zhang Y, et al. Radiotherapy in muscle-invasive bladder cancer: the latest research progress and clinical application. Am J Cancer Res 2015; 5(2): 854-868. (PMID: 25973322)

18. Korpic MC, Blok AM, Martin B, et al. The Impact of Radiation Therapy Dose on Survival in Patients with Muscle-Invasive Bladder Cancer: A Population-Based Analysis. Int J Radiat Oncol Biol Phys (Abstact) 2016; 96(2):S183.

19. Tester W, Porter A, Asbell S, et al. Combined modality program with possible organ preservation for invasive bladder carcinoma: results of RTOG protocol 85-12. Int J Radiat Oncol Biol Phys. 1993; 25(5): 783-790. (PMID: 8478228)

20. Kaufman DS, Winter KA, Shipley WU, et al. Phase I-II RTOG study (99-06) of patients with muscle-invasive bladder cancer undergoing transurethral surgery, paclitaxel, cisplatin, and twice-daily radiotherapy followed by selective bladder preservation or radical cystectomy and adjuvant chemotherapy. Urology 2009; 73(4): 833-837. (PMID: 19100600)

21. Atasoy BM, Dane f, Cetin IA. Concurrent chemoradiotherapy with low dose weekly gemcitabine in medically inoperable muscle-invasive bladder cancer patients. Clinical and Translational Oncology 2014: 16(1); 91-95. (PMID: 23615982)

22. Hoskin PJ, Rojas AM, Bentzen SM, et al. Radiotherapy with concurrent carbogen and nicotinamide in bladder carcinoma. J Clin Oncol 2010; 28(33): 49124918. (PMID: 20956620)

23. James $\mathrm{N}$, Hussain $\mathrm{SA}$, Hall E, et al. Results of a $2 \times 2$ phase III randomized trial of synchronous chemo-radiotherapy compared to radiotherapy alone and standard versus reduced high dose volume radiotherapy in muscle-invasive bladder cancer. J Clin Oncol 2010; 28(p15):(Abstr 4517). DOI:10.1016/j. ijrobp.2010.07.048

24. Hussain SA, Stocken DD, Peake DR, et al. Long-term results of a phase II study of synchronous chemoradiotherapy in advanced muscle-invasive bladder cancer. Br J Cancer. 2004; 90(11): 2106-2111. (PMID: 15150587)

25. Asadauskiene J, Aleknavicius E, Zelviene TP, et al. The value of clinical prognostic factors for survival in patients with invasive urinary bladder cancer. Medicina Kaunas 2010; 46(5): 305-14. (PMID: 20679745) 